\title{
Contribution of residential wood combustion and other sources to hourly winter aerosol in Northern Sweden determined by positive matrix factorization
}

\author{
P. Krecl, E. Hedberg Larsson, J. Ström, and C. Johansson \\ Department of Applied Environmental Science, Atmospheric Science Unit, Stockholm University, Stockholm, Sweden
}

Received: 11 January 2008 - Published in Atmos. Chem. Phys. Discuss.: 19 March 2008

Revised: 15 May 2008 - Accepted: 8 June 2008 - Published: 10 July 2008

\begin{abstract}
The combined effect of residential wood combustion (RWC) emissions with stable atmospheric conditions, which frequently occurs in Northern Sweden during wintertime, can deteriorate the air quality even in small towns. To estimate the contribution of RWC to the total atmospheric aerosol loading, positive matrix factorization (PMF) was applied to hourly mean particle number size distributions measured in a residential area in Lycksele during winter 2005/2006. The sources were identified based on the particle number size distribution profiles of the PMF factors, the diurnal contributions patterns estimated by PMF for both weekends and weekdays, and correlation of the modeled particle number concentration per factor with measured aerosol mass concentrations $\left(\mathrm{PM}_{10}, \mathrm{PM}_{1}\right.$, and light-absorbing carbon $\left.\mathrm{M}_{\mathrm{LAC}}\right)$. Through these analyses, the factors were identified as local traffic (factor 1), local RWC (factor 2), and local RWC plus long-range transport (LRT) of aerosols (factor 3). In some occasions, the PMF model could not separate the contributions of local RWC from background concentrations since their particle number size distributions partially overlapped. As a consequence, we report the contribution of RWC as a range of values, being the minimum determined by factor 2 and the possible maximum as the contributions of both factors 2 and 3. A multiple linear regression (MLR) of observed $\mathrm{PM}_{10}, \mathrm{PM}_{1}$, total particle number, and $\mathrm{M}_{\mathrm{LAC}}$ concentrations is carried out to determine the source contribution to these aerosol variables. The results reveal RWC is an important source of atmospheric particles in the size range 25-606 nm (44-57\%), $\mathrm{PM}_{10}$ (36-82\%), $\mathrm{PM}_{1}$ (31-83\%), and $\mathrm{M}_{\mathrm{LAC}}(40-76 \%)$ mass concentrations in the winter season.
\end{abstract}

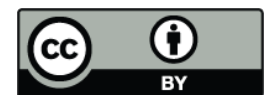

Correspondence to: $\mathrm{P}$. Krecl (patricia.krecl@itm.su.se)
The contribution from RWC is especially large on weekends between 18:00 LT and midnight whereas local traffic emissions show similar contributions every day.

\section{Introduction}

Recently, renewed attention has been paid to residential wood combustion (RWC) as a substantial source of airborne particulate matter (PM) in regions with cold climate. Studies on the impact of RWC on air quality have been conducted in several countries, like Sweden (Hedberg et al., 2006; Krecl et al., 2007; Krecl et al., 2008), Norway (Kocbach et al., 2005), Denmark (Glasius et al., 2006), USA (Gorin et al., 2006), New Zealand (Wang and Shooter, 2002) and Australia (Keywood et al., 2000). In Sweden, the main energy sources for residential heating in 2005 were electricity $(\sim 40 \%)$, combined firewood and electricity $(21 \%)$, followed by exclusively bio-fuel combustion (11\%) (Statistics Sweden, 2005). The energy output from bio-fuels increased by about $70 \%$ between 2000 and 2005 in the whole country. Approximately $61 \%$ of the residential wood boilers have low combustion efficiency and their emissions can be several times larger than modern installations (Johansson et al., 2004). The combined effect of these small scale emissions with stable atmospheric conditions during wintertime, which occur frequently in Northern Sweden, can deteriorate the air quality even in small towns (Krecl et al., 2007; Krecl et al., 2008).

To implement effective strategies to control PM emissions and assess health effects due to poor air quality, source apportionment of atmospheric aerosol is needed in areas with high PM concentrations. Different techniques, such as unique

Published by Copernicus Publications on behalf of the European Geosciences Union. 
emission source tracers, air quality dispersion modeling or source-receptor modeling, can be employed to estimate the contribution of the sources. A number of elemental and molecular tracers (e.g., potassium and chlorine, methyl chloride (Khalil and Rasmussen, 2003), and levoglucosan; Hedberg et al., 2006) have been used to identify and quantify wood smoke. However, the reliability of some of these tracers often suffers from high emission variability and lack of uniqueness. In contrast to these markers, radiocarbon $\left({ }^{14} \mathrm{C}\right)$ measurements provide an unambiguous source apportionment of contemporary and fossil fuel derived carbonaceous aerosol since it retains its identity throughout any atmospheric chemical change (Reddy et al., 2002). In the atmosphere, high temporal resolution measurements of many of these tracers are not possible due to the necessity of large sampling volumes to detect the concentrations accurately. On the other hand, atmospheric dispersion modeling can provide spatial and temporally resolved source contributions but can be difficult to perform accurately since detailed quantitative information of the emissions and meteorology is required, and in some cases also aerosol chemical transformation and removal processes might be considered. Thus, dispersion model calculations need to be validated. Briefly, aerosol source-receptor modeling quantifies the impact of various relevant sources to the concentrations measured at a certain site (the receptor). Among source-receptor models, positive matrix factorization (PMF) has been extensively used for source apportionment of particle composition data, where the goal is to determine the sources that contribute to PM samples (e.g., Hedberg et al., 2005; Hedberg et al., 2006). Lately, PMF has been applied to particle size distribution data to estimate possible sources from model identified particle size distributions (Kim et al., 2004; Zhou et al., 2004). Continuous aerosol size distribution measurements can provide very large data sets with high temporal resolution, which is relevant for source apportionment calculations.

In order to characterize the urban aerosol during the wood burning season in Northern Sweden, a field campaign was conducted in a residential area in winter 2005/2006. In this study, hourly mean particle number size distributions are analyzed using the PMF method to obtain the factor profiles and identify the emission sources. Then a multiple linear regression (MLR) of observed $\mathrm{PM}_{10}, \mathrm{PM}_{1}$, particle number, and light-absorbing carbon concentrations is carried out to determine the source contribution to these aerosol variables on an hourly basis and for the whole measurement period.

\section{Methodology}

\subsection{Aerosol measurements}

The field campaign was carried out in the town of Lycksele $\left(64.55^{\circ} \mathrm{N}, 18.72^{\circ} \mathrm{E}, 240 \mathrm{~m}\right.$ a.s.l., population 8600$)$. The receptor site was placed in Forsdala where RWC is com- mon and local traffic within the area is limited (the closest major road is located $200 \mathrm{~m}$ from the site, $\sim 3000$ vehicles/day). Particles were sized and counted in the diameter range $25-606 \mathrm{~nm}$ with a differential mobility particle sizer (DMPS) composed of a custom-built differential mobility analyzer (DMA, Vienna type) and a condensation particle counter (CPC, TSI 3760, TSI Inc., USA). Particle number concentration was calculated from particle number size distribution and is denoted $\mathrm{N}_{25-606}$, where the subindices indicate the lower and upper bin limit of particle diameters. Total $\mathrm{PM}_{10}$ mass concentrations were provided by a Filter Dynamics Measurement System (FDMS, series 8500 Rupprecht and Patashnick Inc.) whereas total $\mathrm{PM}_{1}$ mass concentrations were measured with a Tapered Element Oscillating Microbalance (TEOM 1400a, Rupprecht and Patashnick Inc., USA). No other correction than the TEOM inbuilt correction (1.3TEOM+3) was applied to the $\mathrm{PM}_{1}$ mass concentrations. A commercial Aethalometer (series 8100, Magee Scientific Inc.) operated with a $\mathrm{PM}_{1}$ sample inlet measured the light-absorbing carbon mass concentration $\mathrm{M}_{\mathrm{LAC}}$. The reader is referred to Krecl et al. (2007) and Krecl et al. (2008) for more operational details on these aerosol measurements. Additionally, $\mathrm{PM}_{10}$ mass concentrations were measured with a TEOM 1400ab (Rupprecht and Patashnick Inc., USA) at Vindeln station. This is a background monitoring station of the Cooperative Program for Monitoring and Evaluation of the Long-Range Transmissions of Air Pollutants in Europe (EMEP), situated in a forest $\sim 65 \mathrm{~km}$ southeast of Lycksele. All measurements from 31 January to 9 March 2006 were averaged on an hourly basis considering a minimum data availability of $75 \%$ per hour.

\subsection{Positive matrix factorization}

PMF is a powerful multivariate least-squares technique that constraints the solution to be non-negative and takes into account the uncertainty of the observed data (Paatero and Tapper, 1994). This method relies on the time-invariance of the source profiles and, thus, requires the emission particle size distributions to be stable in the atmosphere between the sources and the receptor site. According to Zhou et al. (2004), after some initial size distribution changes in the vicinity of the sources (due to coagulation and dry deposition), it is reasonable to expect that particle size distributions will become relatively stable when sampling at some appropriate distance from the emission sources.

The basic source-receptor model in matrix form is:

$\mathbf{X}=\mathbf{G} \cdot \mathbf{F}+\mathbf{E}$,

where $\mathbf{X}$ is the matrix of observed particle number size distributions, $\mathbf{G}$ and $\mathbf{F}$ are, respectively, the source contributions and particle number size distribution profiles of the sources that are unknown and are estimated from the analysis, and $\mathbf{E}$ 
is the residual matrix (observed - estimated). Equation 1 can also be expressed in the element form as:

$x_{i j}=\sum_{k=1}^{p} g_{i k} \cdot f_{k j}+e_{i j}$

where $x_{i j}$ is the particle number concentration of size interval $j$ measured on sample $i, p$ is the number of factors contributing to the samples, $f_{k j}$ is the concentration of size bin $j$ from the $k$ th factor, $g_{i k}$ is the relative contribution of factor $k$ to sample $i$, and $e_{i j}$ is the residual value for the size bin $j$ measured on the sample $i$. For a given $p$, values of $f_{k j}$ and $g_{i k}$ are adjusted using a least-square method (with the constraint that $f_{k j}$ and $g_{i k}$ values are non-negative), until a minimum $Q$ value is found:

$Q=\sum_{i=1}^{n} \sum_{j=1}^{m}\left(\frac{e_{i j}}{\sigma_{i j}}\right)^{2}$.

$\sigma_{i j}$ is the uncertainty of the particle number concentration of size bin $j$ in sample $i, n$ is the number of samples, and $m$ is the number of size intervals.

Following Hedberg et al. (2006), a multiple linear regression model of the g-factors onto the measured concentrations of each aerosol variable (i.e. $\mathrm{N}_{25-606}, \mathrm{M}_{\mathrm{LAC}}, \mathrm{PM}_{10}$, and $\mathrm{PM}_{1}$ ) was performed. The MLR model assumes that the concentrations of each aerosol variable can be expressed as a linear function of the $\mathrm{g}$-factors and determines the regression coefficients and their confidence intervals (95\%). The source contributions to each aerosol variable in then estimated based on the calculated regressions coefficients.

Reff et al. (2007) recommended documenting all of the procedural details used in the PMF application in order to obtain source apportionment results that are of known quality. The next sections describe the data preparation, selection of model parameters, and diverse tests on the PMF runs. A summary of the methodological details chosen for this PMF analysis is shown in Table 1.

\subsubsection{Data preparation}

A total of 769 hourly mean particle number size distributions, each with 18 size intervals, were used in this study after discarding faulty scans. There are several sources of measurement errors for DMPS particle number size distributions. Errors due to particle counting might arise from the CPC detection efficiency, problems in the CPC optics, and large flow rate fluctuations in the CPC. Neither large CPC flow rate variations nor problems associated to the CPC optics were observed during the Lycksele campaign. According to Wiedensohler et al. (1997), the particle detection efficiency for the CPC TSI-3760 operated at $1.51 \mathrm{~min}^{-1}$ is $90 \%$ at $25 \mathrm{~nm}$ and rapidly increases for larger particle diameters. Another error source is related to the particle sizing, being
Table 1. Summary of the PMF methodological details used in this study.

\begin{tabular}{ll}
\hline PMF parameters & Selected option \\
\hline Number of factors $(p)$ & 3 \\
PMF mode & robust \\
Outliers distance $(\alpha)$ & 4 \\
$F_{\text {peak }}$ & {$[-1.6:-1.2]$ in steps of 0.1} \\
Error model & $\sigma_{i j}=C_{i j}+C_{3} \max \left(\left|x_{i j}\right|,\left|y_{i j}\right|\right)$, \\
& with $C_{i j}=0$ and $C_{3}=0.25$ \\
Missing data & Samples were omitted \\
Model uncertainty & $25 \%$ samples randomly removed, \\
& 300 runs \\
\hline
\end{tabular}

the fluctuations of flow rate in the DMA the most important effect in this experiment. The sheath flow rate variation was $1-2 \%$ during the campaign, producing a $2-3 \%$ error in particle size calculations. Particle losses in the system could also lead to measurement errors. In this study, we discard losses produced by diffusion and impaction because of the size range covered by the DMPS. Particle residence times in the DMPS system are very short compared to coagulation time scales and hence losses due to coagulation are negligible. The inversion algorithm included a correction for doubly-charged aerosol particles and a triangular-shape transfer function was implemented. The fraction of triplycharged particles is lower than $8 \%$ at $600 \mathrm{~nm}$ where usually low particle concentrations are measured. As a result, if triply-charged particles at $600 \mathrm{~nm}$ are wrongly assigned to a smaller size bin their effect might be negligible.

\subsubsection{Selection of PMF parameters}

\section{Number of factors}

Different factor numbers were tested and a 3-factor model adequately fitted the data with the most meaningful results. When 4 factors were included in the analysis, no more relevant sources could be identified.

\section{Rotations}

As other factor analysis techniques, PMF suffers from rotational indeterminacy of the solution as extensively discussed by Paatero et al. (2002). $F_{\text {peak }}$ is the model parameter that controls the rotation in PMF by adding and/or subtracting the rows and columns of $\mathrm{F}$ and $\mathrm{G}$ matrices from each other depending on the sign of the $F_{\text {peak }}$ value. Diverse methods have been proposed to adjust $F_{\text {peak }}$ to obtain the most meaningful results (Paatero et al., 2002; Paatero et al., 2005). Usually,

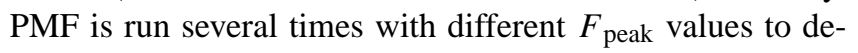
termine the range within which the $Q$ value remains stable (Paatero et al., 2002). Figure 1a shows the $Q$ values obtained when a 3 -factor PMF model was run for $F_{\text {peak }}$ values 

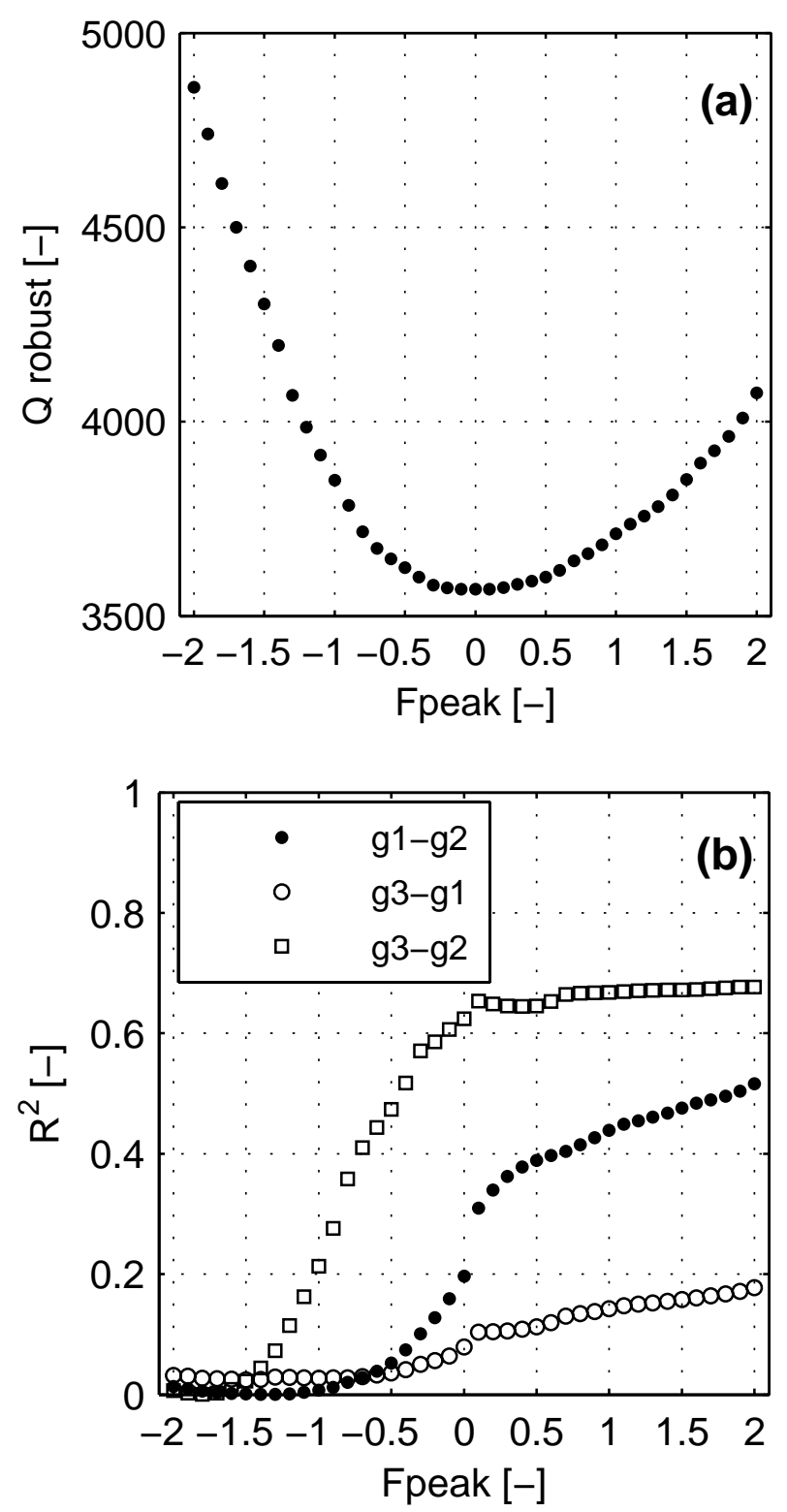

Fig. 1. (a) $F_{\text {peak }}$ values versus $Q$ robust values for PMF. (b) Coefficient of determination $\left(R^{2}\right)$ among g-factors $(\mathrm{g} 1, \mathrm{~g} 2, \mathrm{~g} 3)$ versus $F_{\text {peak }}$ values. PMF was run using three factors, $C_{3}=0.25$, and $\alpha=4$. $[-]$ denotes the variable is dimensionless.

between -2 and +2 in steps of 0.1 . Based on Paatero et al. (2005), the coefficients of determination $R^{2}$ among the three g-factors are plotted as a function of $F_{\text {peak }}$ in Fig. 1b. The PMF solutions for $F_{\text {peak }} \geq 0$ resulted in negative regression coefficients when the factor contributions were regressed onto $\mathrm{PM}_{1}$ mass concentrations and, thus, these solutions are considered physically invalid. It can be observed that the statistical independence between pairs of $g$-factors increases for decreasing $F_{\text {peak }}$ values (all $R^{2}$ were lower than 0.1 for $F_{\text {peak }} \leq-1.2$ ). Thus, the selection of $F_{\text {peak }}$ is re- stricted to values smaller than -1.1 . Another approach to reduce the rotational ambiguity is to use some a priori information that helps constraining the solution. In our case, we employ $\mathrm{PM}_{10}$ mass concentration measured at a background site (Vindeln). Figure 2 shows the temporal series of the modeled $\mathrm{PM}_{10}$ contribution per factor for $F_{\text {peak }}=-0.1$ (maximum valid value) and $F_{\text {peak }}=-1.4$ (panels a, b, and c) together with observed $\mathrm{PM}_{10}$ mass concentrations at Vindeln (panel c). As will be discussed in Sect. 3.1, factor 1 can be interpreted mostly as the contribution from local traffic, factor 2 as local RWC, whereas factor 3 is a combination of two sources: local RWC and long-range transport (LRT). The largest difference in $\mathrm{PM}_{10}$ mass concentration when running PMF for $F_{\text {peak }}=-0.1$ and -1.4 is found for factors 2 and 3. When PMF is run for $F_{\text {peak }}=-1.4$, a larger contribution of factor 2 (mostly local RWC) to $\mathrm{PM}_{10}$ is found whereas the local RWC contribution to factor 3 is reduced and the correlation with Vindeln background measurements increases. For $F_{\text {peak }}<-1.6$, the contribution of factor 3 to $\mathrm{PM}_{10}$ is mostly below the observed background contribution. As a result of these tests, we selected a range of $F_{\text {peak }}$ values between -1.6 and -1.2 . For the sake of completeness, the time series of modeled aerosol variables $\mathrm{M}_{\mathrm{LAC}}, \mathrm{N}_{25-606}$, and $\mathrm{PM}_{1}$ together with the observed data are presented in the appendix (Figs. A1, A2, A3).

\section{Error model}

A dynamical error model was chosen for this study and PMF uncertainties are calculated at each iteration step of the program by using the formula shown in Table 1 . In this expression, the uncertainty $\sigma_{i j}$ is derived from the measurement error $C_{i j}$, the constant $C_{3}$ and the maximum value between the observed $x_{i j}$ and the modeled $y_{i j} . C_{3}$ is included to account for some source profile variation and, in this way, provides the fitting more flexibility to accommodate this variability. As previously shown, the DMPS measurement error was quite small and, hence, we decided to set $C_{i j}$ to 0 and include all the uncertainty input in the $C_{3}$ constant. In order to obtain small scaled residuals, $C_{3}$ was set up to 0.25 .

\section{Robust mode and outliers}

PMF was run in the robust mode to reduce the influence of atypical measurements in the dataset. In this mode, the uncertainties of measurements for which the scaled residuals are larger than the outlier threshold distance $\alpha$ are increased to diminish their influence on the PMF solution. As suggested by Paatero (2000), standard $\alpha$ values of 2, 4 (default value), and 8 were tested in this study. The test was carried out with a 3 -factor model, $F_{\text {peak }}=-1.4$, and $C_{3}=0.25$. No difference between the solutions using $\alpha=4$ and $\alpha=8$ was observed since the scaled residuals for both runs lay in the range $[-2,3.4]$. Small differences in $\mathrm{f}$ and $\mathrm{g}$-factors were found when PMF was run with $\alpha=2$ compared to the default 


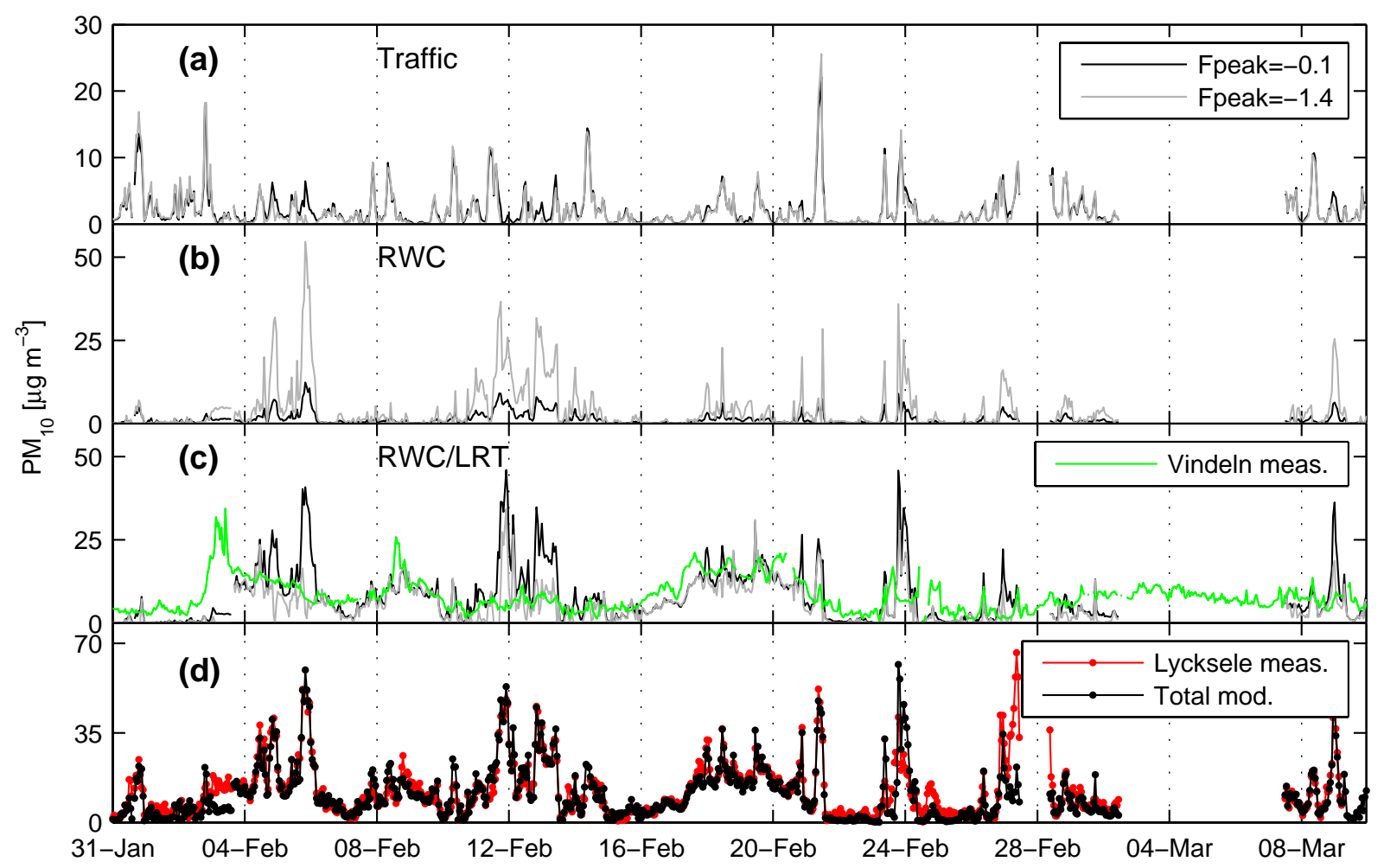

Fig. 2. Time series of modeled $\mathrm{PM}_{10}$ contribution for each factor for $F_{\text {peak }}=-0.1$ and $-1.4(\mathbf{a}),(\mathbf{b})$, (c), together with total modeled and measured $\mathrm{PM}_{10}$ concentrations (d). $\mathrm{PM}_{10}$ mass concentration at Vindeln (rural background site) is also shown in panel c.

$\alpha$ value. Emulated aerosol concentrations $\left(\mathrm{N}_{25}-606, \mathrm{M}_{\mathrm{LAC}}\right.$, $\mathrm{PM}_{10}$, and $\mathrm{PM}_{1}$ ) were compared when running PMF with $\alpha=2$ and $\alpha=4$. The largest mean difference between aerosol concentrations $(25 \%)$ was observed for the contribution of factor 2 to $\mathrm{PM}_{1}$ mass concentrations. This indicates, once more, that $\mathrm{PM}_{1}$ is the most sensitive aerosol variable in relation to PMF initialization parameters in this study. As a result, PMF was run with $\alpha=4$ in this work.

\subsubsection{Tests on PMF runs}

\section{Global minimum}

Least-squares can yield multiple solutions depending on the initial starting point for each entry in the $\mathbf{F}$ and $\mathbf{G}$ matrices. PMF was run 5 times with different seed values to ensure that a global minimum has been reached. The setup of the initialization PMF parameters was: $F_{\text {peak }}=-1.4, C_{3}=0.25$, 3 factors and $\alpha=4$. The same output values ( $f$ and $g$-factors, and $Q$ ) were obtained for all the runs. Hence, we conclude that the PMF solution consistently converges and a global minimum was found for this particular setup of model parameters.

\section{Goodness of model fit}

Two methods were employed to assess the adequacy of the PMF fit to the measurements. First, the distribution of scaled residuals was examined when using a 3 -factor model $\left(F_{\text {peak }}=-1.4, C_{3}=0.25\right.$, and $\left.\alpha=4\right)$. The residual concentrations are normally distributed and no structured features were identified. Second, the modeled aerosol concentrations were compared to the measurements. Time series of observed and total modeled concentrations of $\mathrm{PM}_{10}, \mathrm{PM}_{1}, \mathrm{M}_{\mathrm{LAC}}$, and $\mathrm{N}_{25-606}$ are displayed in Figs. 2d, A1d, A2d and A3d, respectively. Figure 3 shows scatter plots and least-squares linear regressions between modeled and observed $\mathrm{PM}_{10}, \mathrm{PM}_{1}$, $\mathrm{M}_{\mathrm{LAC}}$ and $\mathrm{N}_{25-606}$ concentrations. The $95 \%$ confidence intervals for the slope and intercept were also calculated and included in the linear regression equation. As expected, the highest $R^{2}$ and slope close to 1 was obtained for $\mathrm{N}_{25-606}$ since PMF was run on particle number size distributions. The variability of the measured $\mathrm{M}_{\mathrm{LAC}}$, is very well predicted by the model $\left(R^{2}=0.85\right)$ whereas for $\mathrm{PM}_{10}$, and $\mathrm{PM}_{1}$ the coefficients of determination are 0.75 and 0.72 , respectively. The intercept seen in Fig. $3 \mathrm{~b}$ ( $\mathrm{PM}_{1}$ linear regression) is significantly different from zero at $95 \%$ confidence interval. This might suggest the inbuilt correction for the loss of volatile material applied by the TEOM instrument is not adequate for the measurements carried out in this Lycksele campaign. 

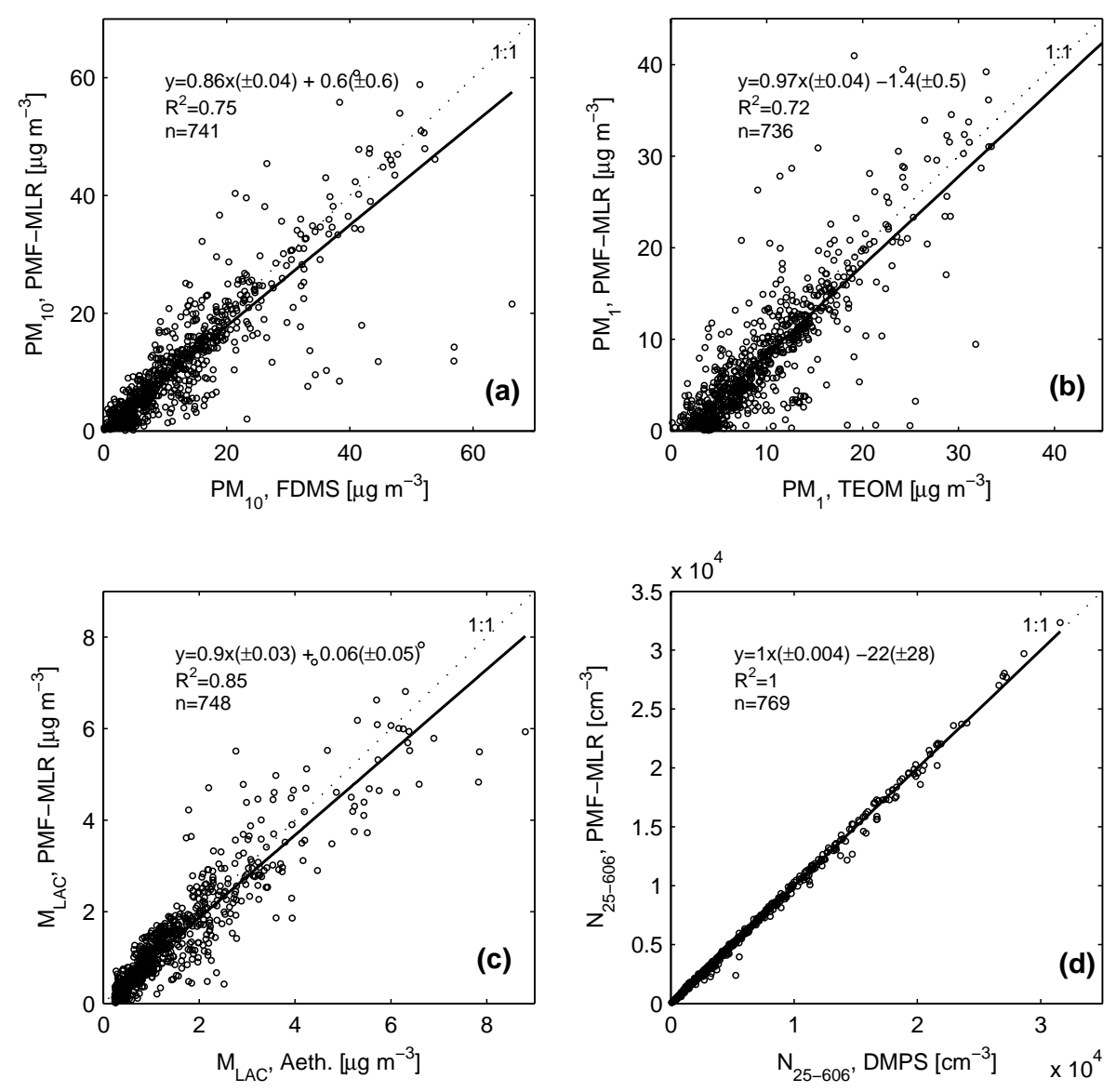

Fig. 3. Scattergram of predicted (PMF-MLR) vs. measured concentrations of: (a) $\mathrm{PM}_{10}$, (b) $\mathrm{PM}_{1}$, (c) $\mathrm{M}_{\mathrm{LAC}}$, and (d) $\mathrm{N}_{25-606}$. The $95 \%$ confidence intervals for the slope and intercept are included in the linear regression equation (in parenthesis). The solid line represents the least squares line regression and the dotted line indicates the identity line (1:1). The number of samples $n$ and coefficient of determination $R^{2}$ are also shown.

Hedberg et al. (2006) reported a similar problem when performing PMF on $\mathrm{PM}_{2.5}$ mass concentrations measured with a TEOM series 1400 in a previous winter campaign in Lycksele.

\section{Model uncertainties}

Following Hedberg et al. (2005), in order to estimate the model uncertainties $25 \%$ of the original samples were randomly removed and then PMF was run 300 times on these new datasets (always with 3 factors, $C_{3}=0.25, \alpha=4$, and $\left.F_{\text {peak }}=-1.4\right)$. Figure 4 presents the mean and standard deviation of the factor profiles. The difference between the mean factor profiles after removing $25 \%$ of the samples, and the factor profiles when all samples (using the same model initialization values) are included lies between one standard deviation values. As a result, the PMF solution is considered stable.

\section{Results and discussion}

\subsection{Source identification}

The sources were identified based on the particle number size distribution profiles of the PMF factors (Fig. 5), the diurnal contributions patterns estimated by PMF for both weekends (WE) and weekdays (WD) (Fig. 6), and correlation of the modeled $\mathrm{N}$ values with measured aerosol concentrations $\left(\mathrm{PM}_{10}, \mathrm{PM}_{1}\right.$, and $\left.\mathrm{M}_{\mathrm{LAC}}\right)$. Time series of particle number contributions for each factor are presented in the appendix (Fig. A3). Figure 5 displays the calculated factor profiles when the PMF model was run with $F_{\text {peak }}$ values ranging from -1.6 to -1.2 in steps of 0.1 . The left panels show mean modeled particle number size distributions per factor whereas normalized f-factor profiles (mean \pm standard deviation) to the total number of particles per factor are presented in Fig. 5d. This right panel highlights the contribution of each size bin to the total number particle concentration per factor. 


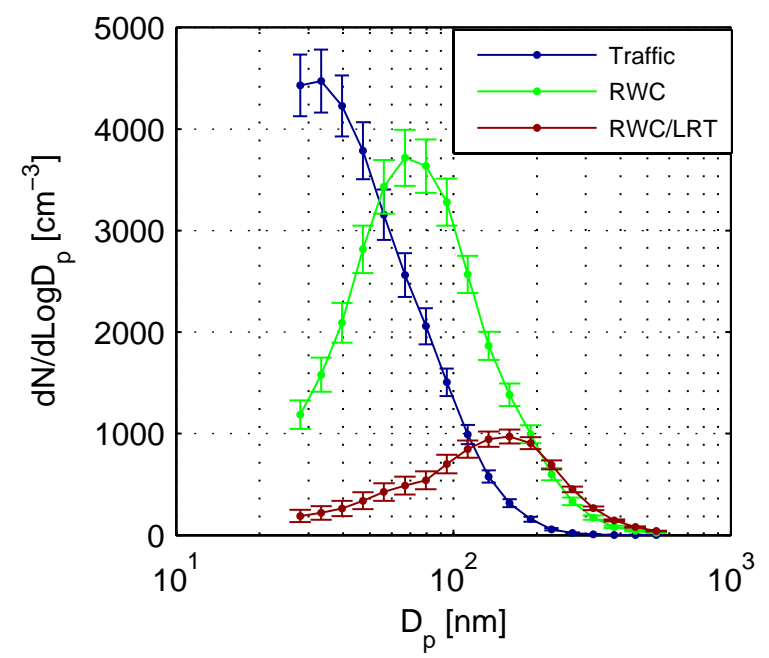

Fig. 4. Mean f-factors and $1 \mathrm{STD}$ error bars as a result of randomly removing $25 \%$ of the original samples. PMF was run 300 times using three factors, $C_{3}=0.25, \alpha=4$, and $F_{\text {peak }}=-1.4$.

Factor 1 has a peak at particle diameter $D_{p} \sim 28 \mathrm{~nm}$ (Fig. 5a) and shows a very well defined daily pattern during weekdays and weekends (Fig. 6a). The strong diurnal variation might suggest that these particles are produced in the immediate vicinity of the receptor site. The origin of this factor is likely to be local traffic emissions. The shape of this modeled profile is similar to the shape of particle number size distributions measured at a street canyon (Gidhagen et al., 2004) and road tunnel (Kristensson et al., 2004) sites in Stockholm where traffic is mainly dominated by gasoline vehicles. The peak number concentration in Stockholm was observed at $D_{p} \sim 20 \mathrm{~nm}$ for both studies, which could not be observed in our case since DMPS measurements started at $25 \mathrm{~nm}$. In Sweden, only 5\% of passenger cars are diesel vehicles and heavy-duty vehicles comprise $5 \%$ of the total vehicle fleet (SIKA, 2006). The weak correlation $(R=0.37)$ we found between modeled $\mathrm{N}_{25-606}$ for factor 1 and measured $\mathrm{M}_{\mathrm{LAC}}$ could be explained by the dominant gasoline vehicles emissions since gasoline vehicles produce lower $\mathrm{M}_{\mathrm{LAC}}$ than diesel engines (Burtscher, 2000; Gillies and Gertler, 2000).

Factor 2 is strongly associated with the light absorbing carbon content of fine aerosols as shown by the high correlation ( $R=0.76$ ) between modeled $\mathrm{N}_{25-606}$ (attributed to factor 2) and the observed $\mathrm{M}_{\mathrm{LAC}}$. Kim et al. (2004) also found a similar correlation between modeled particle size distributions attributed to RWC and light absorption coefficients in Seattle (USA) during wintertime. In Lycksele, particle number concentrations are significantly higher on weekends than on weekdays after 13:00 LT (unpaired t-test, 95\% confidence interval), reaching mean concentrations of $\sim 1 \times 10^{4} \mathrm{~cm}^{-3}$ from 21:00 LT to midnight (Fig. 6b). Several studies (e.g., Hueglin et al., 1997; Hedberg et al., 2002; Johansson et al., 2004; Boman, 2005) have shown that particle size distributions from wood combustion under controlled laboratory condi-
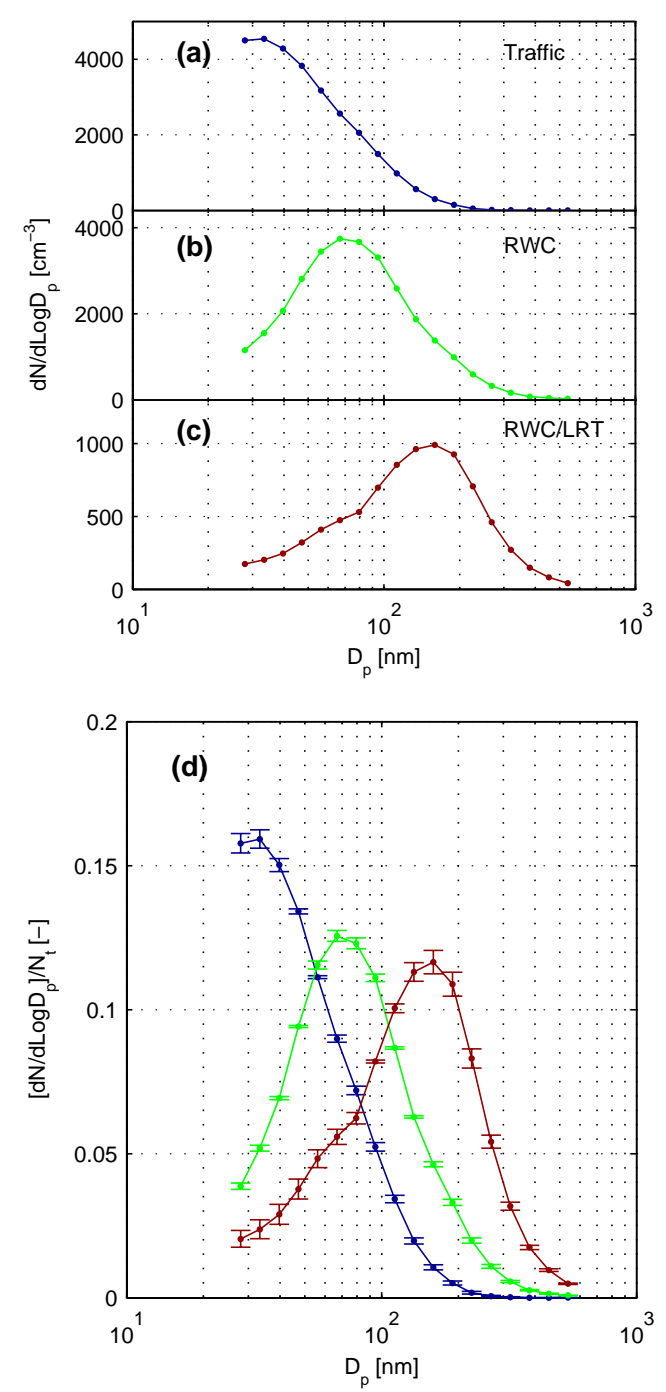

Fig. 5. Left panels: Absolute mean f-factors expressed in $\left[\mathrm{cm}^{-3}\right]$. Right panel: Normalized f-factor profiles (mean \pm standard deviation) to the total number of particles per factor. PMF was run with $F_{\text {peak }}$ values from -1.6 to $-1.2, C_{3}=0.25$, and $\alpha=4$. [-] denotes the variable is dimensionless.

tions vary in shape, peak concentration value and mode diameter depending on a number of factors such as the combustion phase (i.e. ignition, intermediate, and smoldering), appliance type (e.g. wood stove, boiler, fireplace), type and amount of wood, and wood moisture content. Despite of this broad variation, a consistent conclusion is that RWC emits particles mainly in the size range $60-300 \mathrm{~nm}$. As shown in Fig. $5 \mathrm{~b}$, factor 2 peaks at $\sim 70 \mathrm{~nm}$ and its shape is similar to the shape of particle number size distributions measured in winter field campaigns (Kristensson, 2005; Hering et al., 2007) when wood burning was an important particle emission source. Local RWC emissions are suggested to be the source of this factor. 


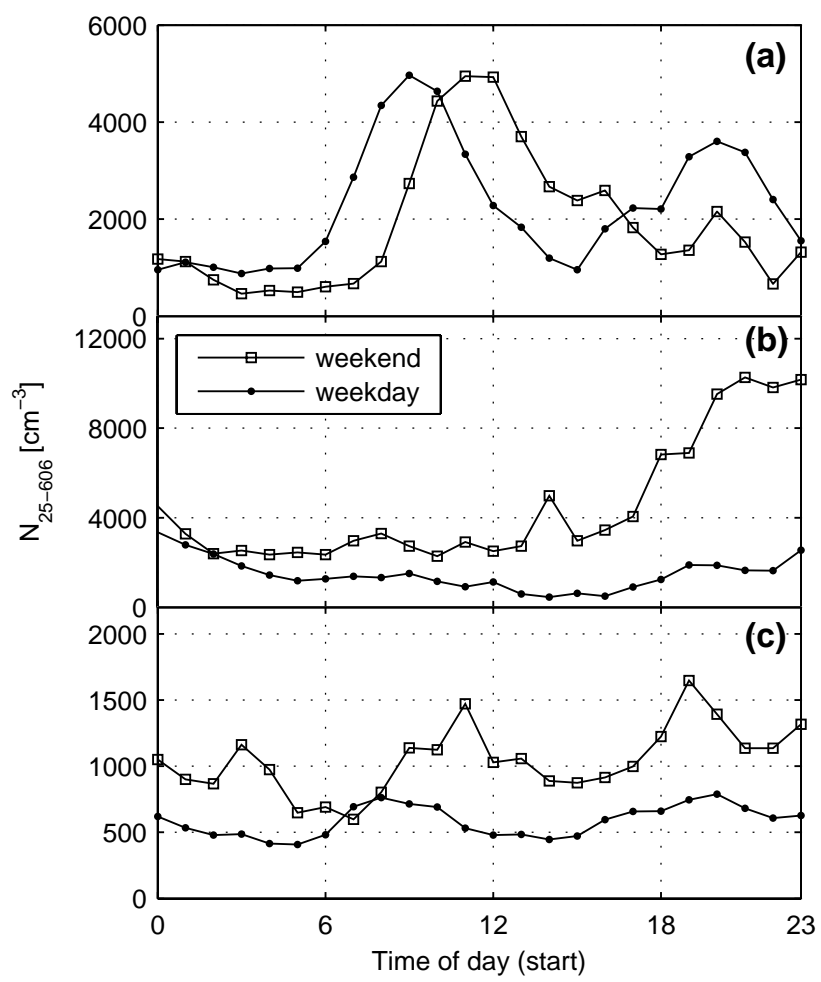

Fig. 6. Comparison of model resolved hourly contributions to $\mathrm{N}_{25-606}$ between weekends and weekdays. (a) Traffic. (b) RWC. (c) RWC/LRT. PMF 3-factor model was run with $F_{\text {peak }}=-1.4$, $C_{3}=0.25$, and $\alpha=4$.

Factor 3 particle number size distribution is depicted in Fig. $5 \mathrm{c}$ and peaks at $\sim 160 \mathrm{~nm}$. We suggest this factor could be a combination of two sources: local wood combustion and long-range transport of particles. Tunved et al. (2003) found that particle number size distributions are typically bimodal (mean mode diameters at $\sim 56 \mathrm{~nm}$ and $160-190 \mathrm{~nm}$ ) during winter in five Nordic background stations (covering latitudes $58^{\circ} \mathrm{N}-68^{\circ} \mathrm{N}$ ). They observed a gradient in the mean daily integral number concentration from $\sim 2000 \mathrm{~cm}^{-3}$ at the southernmost station to values $<500 \mathrm{~cm}^{-3}$ at the two northernmost sites. The diurnal variation of the integrated particle number concentration was small, typically below $\pm 10 \%$ for all sites, indicating limited local anthropogenic sources influence. In our study, modeled $\mathrm{N}_{25-606}$ values for factor 3 are higher on weekends than on weekdays, and this difference is statistically significant (unpaired t-test, $95 \%$ confidence interval) in the time periods: 03:00-04:00 LT, 11:00-14:00 LT, and 18:00-19:00 LT. The mean $\mathrm{N}_{25-606}$ for factor 3 is $586 \mathrm{~cm}^{-3}$ on WD and $1043 \mathrm{~cm}^{-3}$ during WE and the standard deviation of the hourly mean values are $\pm 24 \%$ and $\pm 20 \%$, respectively. These results suggest factor 3 might be influenced by some local human sources.
As discussed above, RWC can produce substantially different particle size distributions with different particle diameters at peak number concentrations. During less efficient combustion the number concentration of fine particles in the emission tend to decrease and the particle size increases compared to more optimized combustion conditions (Boman, 2005). In this study, number size distributions from local RWC (poorer combustion conditions) and LRT might partially overlap. It has been shown in Sect. 2.2.2 that by finetuning the $F_{\text {peak }}$ value one can force the model to detach the local aerosol contribution (attributed to RWC) from the longrange transport contribution. However, as shown in Fig. 6c, it was not possible to completely isolate the LRT contribution in factor 3. Unfortunately, no particle size distribution measurements were simultaneously carried out in a background site close enough to Lycksele to subtract them from the measurements conducted in Lycksele before performing the PMF analysis. Even though the individual contribution of these two sources to the hourly atmospheric aerosol concentrations cannot be determined we can estimate a range of possible contributions. The local RWC contribution to atmospheric aerosol then might vary between the contribution of factor 2 (i.e. factor 3 is all attributed to LRT) and the contributions of factors 2 and 3 (i.e. factor 3 is all attributed to local RWC in this case).

\subsection{Source apportionment}

The mean contributions of the three factors to the total number of particles in the size range $25-606 \mathrm{~nm}$ are $42.6 \%$ (factor 1), $43.7 \%$ (factor 2) and $13.7 \%$ (factor 3 ). Assuming spherical particles and calculating the volume concentration from the modeled number concentration, the mean contributions per factor to the total volume concentration are $8.6 \%, 43.9 \%$, and $47.5 \%$ for factors 1,2 , and 3, respectively.

Besides using the particle number size distributions of the PMF factors as a method to identify the sources, one can gain some knowledge on the contribution of each factor to certain particle diameter. Figure 7a displays the contribution of the factors to the total modeled particle number size distribution $\left(F_{\text {peak }}=-1.4, C_{3}=0.25\right.$, and $\left.\alpha=4\right)$ together with the mean observed size distribution in the period 31 January-9 March 2006. The difference between the total modeled and the mean observed particle size distributions is very small $(<7 \%)$ for all particle diameters. The relative cumulative contribution per factor to the number and volume concentrations as a function of the diameter are shown in Fig. 7b and c, respectively. In order to correctly interpret this figure, we give an example related to the Aitken mode particles (defined, in this study, as particles with $28<D_{p}<100 \mathrm{~nm}$ ). It can be seen in Fig. 7b that these particles account for $77 \%$ of the mean measured particle number concentration (black line). If we want to know the contribution of each factor to the particles measured in the Aitken mode, we check the other 3 curves: blue (factor 1), green (factor 2), and red (factor 


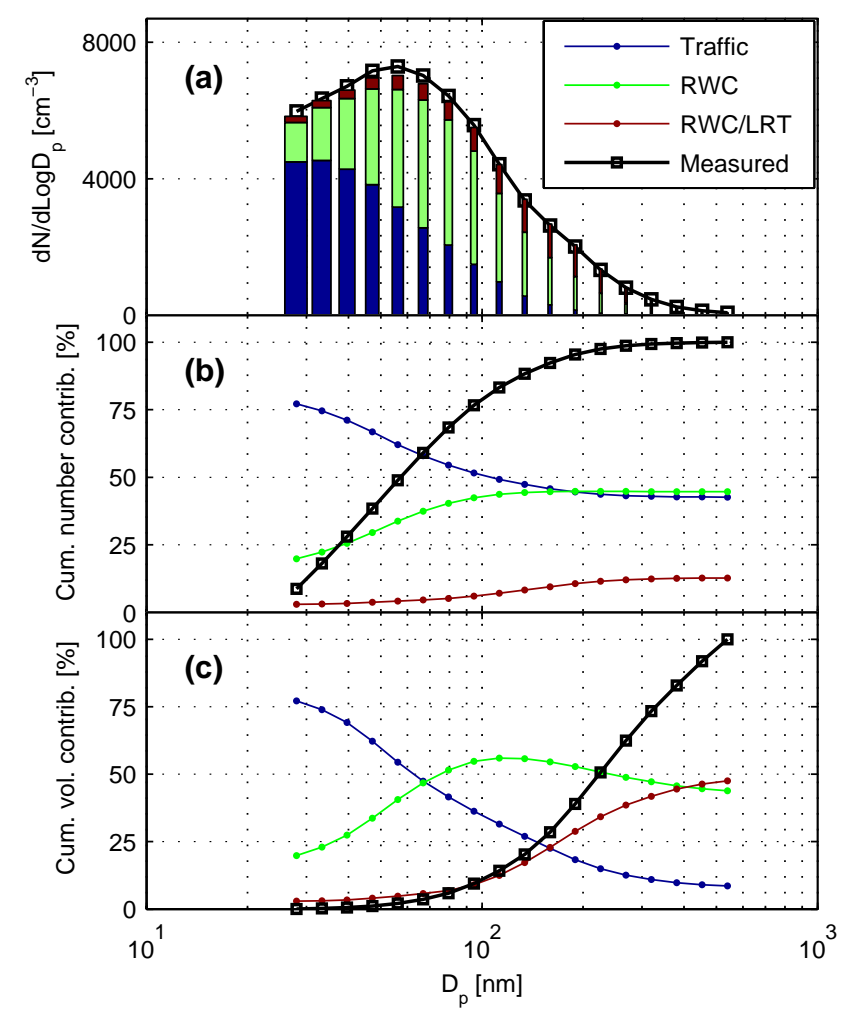

Fig. 7. Cumulative contribution per factor as a function of particle diameter and mean measured particle size distribution. (a) Absolute particle number concentrations. (b) Relative number concentration. (c) Relative volume concentration considering spherical particles. PMF 3-factor model was run with $F_{\text {peak }}=-1.4, C_{3}=0.25$, and $\alpha=4$.

$3)$. For example, the contribution of factor 1 for the smallest particles is quite large (77\%) and decreases to $50 \%$ for $D_{p}=100 \mathrm{~nm}$. Considering all particle diameters now, factor 1 has the largest contribution at the smallest sizes and then decreases maintaining a nearly constant particle emission of $44 \%$ for $D_{p}>190 \mathrm{~nm}$. Factor 2 provides $20 \%$ of the particles at the smallest diameter and its contribution increases to $\sim 45 \%$ and remains constant for larger particles. Factor 3 has a low overall contribution to particle number concentrations that slightly increases when increasing the particle diameter. The same interpretation applies to Fig. 7c but now considering volume fractions instead of number fractions. Factor 2 has the largest factor contribution to volume (mass) concentration for $80<D_{p}<380 \mathrm{~nm}$ whereas factor 1 dominates for $D_{p}<80 \mathrm{~nm}$. The contribution of factor 3 to volume (mass) concentration as a function of increasing $D_{p}$ varies from $3 \%$ to $\sim 50 \%$.

Figure 8 summarizes the mean contribution of the modeled factors to the aerosol concentrations $\left(\mathrm{PM}_{10}, \mathrm{PM}_{1}, \mathrm{M}_{\mathrm{LAC}}\right.$, and $\mathrm{N}_{25-606}$ ) for weekends, weekdays, and all days together in the period 31 January-9 March 2006. The mean contribution of local traffic to the aerosol concentration is similar on
Table 2. Summary of modeled sources contributions to $\mathrm{PM}_{10}$, $\mathrm{PM}_{1}, \mathrm{M}_{\mathrm{LAC}}$, and $\mathrm{N}_{25-606}$ concentrations. The mean contribution of local traffic is displayed whereas minimum and maximum contributions of local RWC and LRT are presented for the period 31 January-9 March 2006. PMF was run with $F_{\text {peak }}=-1.4, C_{3}=0.25$, and $\alpha=4$.

\begin{tabular}{lccc}
\hline Variable & Local traffic (\%) & Local RWC (\%) & LRT (\%) \\
\hline $\mathrm{PM}_{10}$ & 18 & $(36-82)$ & $(0-46)$ \\
$\mathrm{PM}_{1}$ & 17 & $(31-83)$ & $(0-52)$ \\
$\mathrm{M}_{\mathrm{LAC}}$ & 24 & $(40-76)$ & $(0-36)$ \\
$\mathrm{N}_{25-606}$ & 43 & $(44-57)$ & $(0-13)$ \\
\hline
\end{tabular}

weekdays and weekends $\left(2.1\right.$ vs. $1.8 \mu \mathrm{g} \mathrm{m}^{-3}$ for $\mathrm{PM}_{10}, 1.4$ vs. $1.1 \mu \mathrm{g} \mathrm{m}^{-3}$ for $\mathrm{PM}_{1}, 0.3$ vs. $0.32 \mu \mathrm{g} \mathrm{m}^{-3}$ for $\mathrm{M}_{\mathrm{LAC}}$, and 2264 vs. $1894 \mathrm{~cm}^{-3}$ for $\left.\mathrm{N}_{25-606}\right)$. On the other hand, the impact of local RWC on atmospheric aerosol varies depending on the day of the week and the aerosol variable analyzed. Factor 3 has a larger impact on aerosol mass concentrations (i.e. $\mathrm{PM}_{10}, \mathrm{PM}_{1}, \mathrm{M}_{\mathrm{LAC}}$ ) than on particle number concentrations. This is consistent with factor 3 providing less but bigger particles that contribute more to the total mass than the particles emitted by local traffic emissions (factor 1) which are more in number but have smaller sizes.

To facilitate the comparison between our results and other source apportionments studies, Table 2 summarizes the emission sources relative contribution to $\mathrm{PM}_{10}, \mathrm{PM}_{1}, \mathrm{M}_{\mathrm{LAC}}$, and $\mathrm{N}_{25-606}$ concentrations for the whole campaign in Lycksele (31 January-9 March 2006). The mean contribution of local traffic is displayed whereas minimum and maximum mean contributions of local RWC and LRT are presented. Two previous source apportionment studies of ambient aerosol were performed in Lycksele using source-receptor modeling (Kristensson, 2005; Hedberg et al., 2006) on measurements carried out in winter 2001/2002. In our study, the largest impact of local traffic is on particle number concentrations, accounting for $\sim 43 \%$ of particle number concentrations in the diameter range 25-606 nm. Kristensson (2005), using COPREM model on particle number size distributions, attributed $38 \%$ of particle number concentrations between 3 and $850 \mathrm{~nm}$ to local traffic in Lycksele in the period 14 January-9 March 2002. Another 38\% was classified by Kristensson (2005) as the contribution of local RWC whereas LRT accounted for the remaining $24 \%$. This last value is larger than the possible maximum mean $\mathrm{N}_{25-606}$ value we estimated for the LRT contribution $(13 \%)$. This difference could be related to different air quality characteristics (different sampling years), different DMPS cut-off sizes, and also to the method chosen by Kristensson (2005) to estimate the average background contribution. The same problem related to the interference between local RWC and LRT particle number size distributions was encountered by Kristensson (2005). To overcome this difficulty, the background 

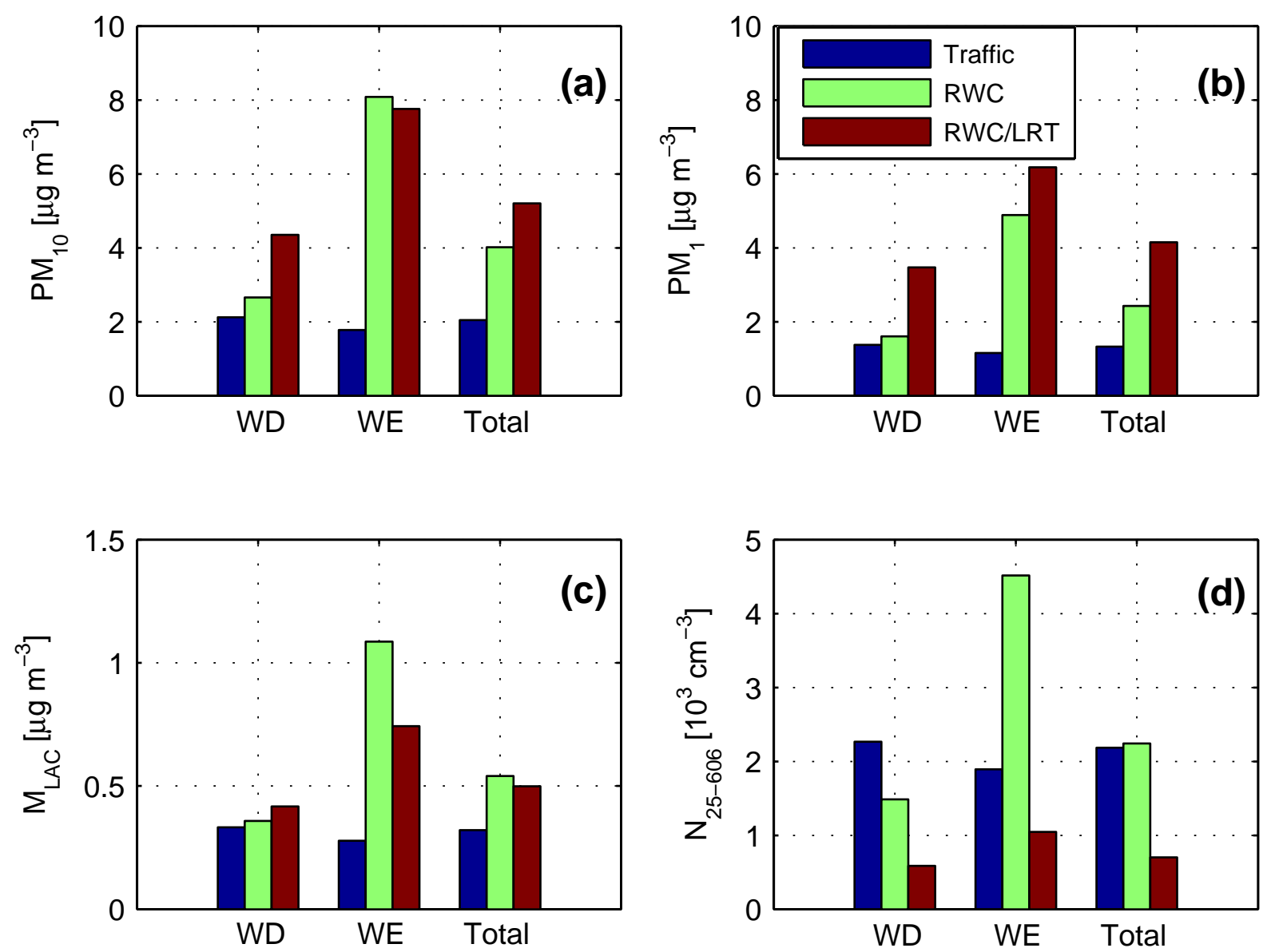

Fig. 8. Summary of the mean contribution of the three factors to $\mathrm{PM}_{10}, \mathrm{PM}_{1}, \mathrm{M}_{\mathrm{LAC}}$, and $\mathrm{N}_{25-606}$ for weekdays (WD), weekends (WE) and the whole campaign (Total), in the period 31 January -9 March 2006. PMF was run with $F_{\text {peak }}=-1.4, C_{3}=0.25$, and $\alpha=4$.

contribution to particle number concentration was calculated as the average of measurements at two background stations (Hyytiälä and Pallas) for the winter 2002. Hedberg et al. (2006) apportioned $70 \%$ of $\mathrm{PM}_{2.5}$ mass concentration to local RWC when performing a PMF analysis on inorganic compounds and using mainly the abundance of $\mathrm{K}$ and $\mathrm{Zn}$ to identify this combustion source. This fraction apportioned by Hedberg et al. (2006) lies within the local RWC contribution intervals we estimated for $\mathrm{PM}_{10}$ and $\mathrm{PM}_{1}$ mass concentrations and might suggest the local RWC contribution is closer to the possible maximum fraction (very low background contribution to factor 3 ) than to the minimum possible value (factor 3 is all LRT). Finally, our apportionment of $\mathrm{M}_{\mathrm{LAC}}$ can be roughly compared to the radiocarbon analysis results of total carbon reported by Sheesley et al. $\left(2008^{1}\right)$ when sampling in Lycksele from 23 January to 8 March

1 Sheesley, R. J., Kruså, M., Krecl, P., Johansson, C., and Gustaffson, Ö.: Source apportionment of elevated wintertime PAHs in a northern Swedish town by compound specific radiocarbon analysis, Environ. Sci. Technol., submitted, 2008.
2006. Total carbon is defined as the carbon remaining after removal of the inorganic carbonates by acid treatment and, thus, includes elemental and organic carbon. If we assume that the fossil total carbon fraction absorbs light in the same amount as the modern total carbon fraction does, then the apportionment found with radiocarbon analysis might apply to the $\mathrm{M}_{\mathrm{LAC}}$ data. To correctly interpret and compare these results, the reader has to bear in mind that ${ }^{14} \mathrm{C}$ analysis provides the apportionment of modern and fossil carbonaceous aerosol but does not provide information on the location of the emission sources (local or LRT). The average contribution of fossil total carbon (attributed to traffic emissions) was $24 \%$ which coincides with the mean fraction of $\mathrm{M}_{\mathrm{LAC}}$ we attributed to local traffic emissions. The other $76 \%$ was mostly attributed to wood combustion since biogenic emissions and combustion of grass fires and incineration of household vegetable waste were not observed in the area. Another study in the Nordic region (Glasius et al., 2006) reported two main sources of ambient aerosol when performing COPREM model calculations on $\mathrm{PM}_{2.5}$ mass concentrations measured in a residential area in Denmark 

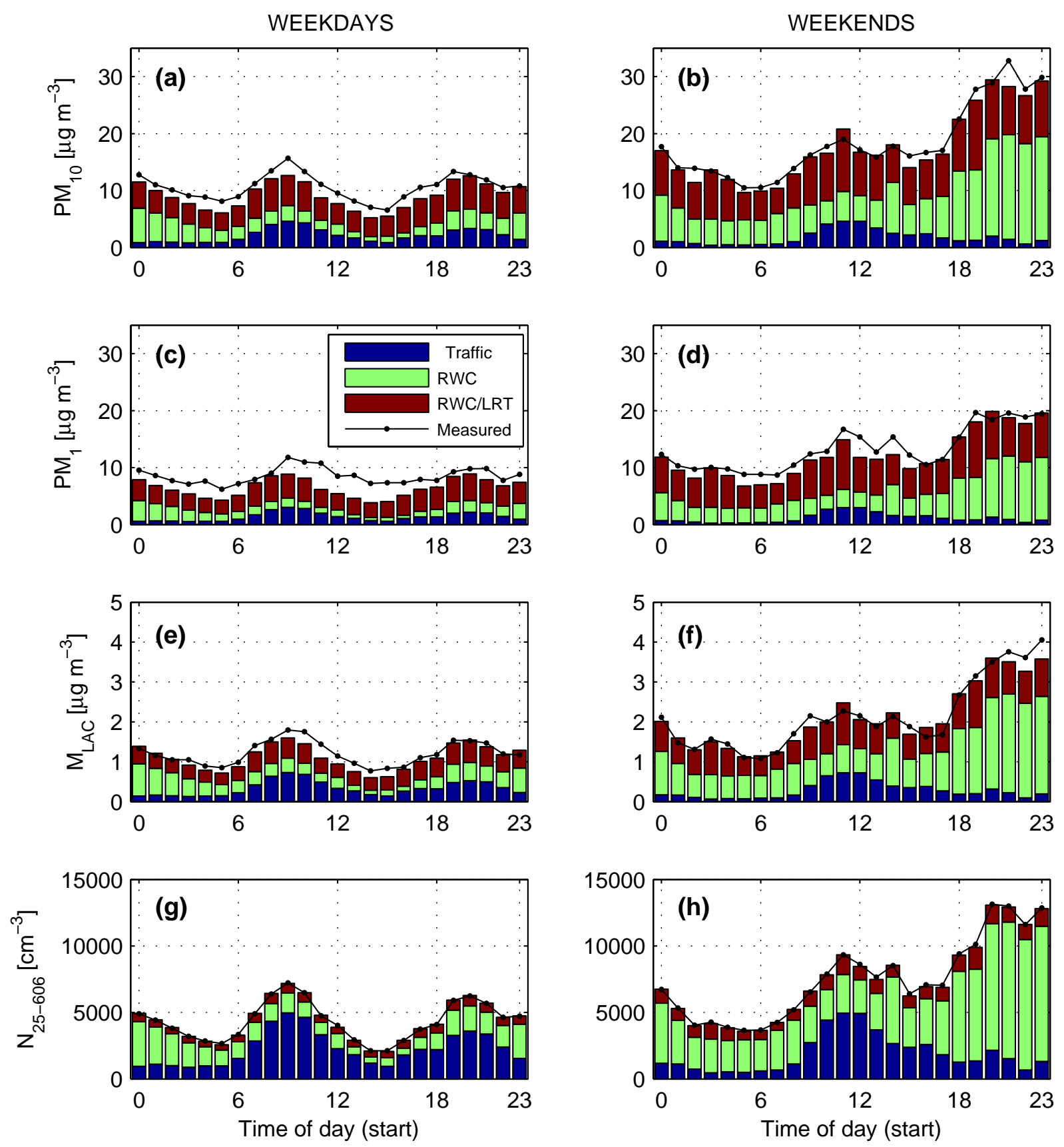

Fig. 9. Model resolved mean diurnal contributions per factor to $\mathrm{PM}_{10}, \mathrm{PM}_{1}, \mathrm{M}_{\mathrm{LAC}}$ and $\mathrm{N}_{25-606}$ for weekdays (left panels) and weekends (right panels). The daily mean measured concentrations are also shown with black lines. PMF 3-factor model was run with $F_{\text {peak }}=-1.4$, $C_{3}=0.25$, and $\alpha=4$.

in winter 2003/2004. The largest contribution to $\mathrm{PM}_{2.5}$ was assigned to long-range transport (mean $10.65 \mu \mathrm{g} \mathrm{m}^{-3}$ ) with additional and episodically contributions from RWC (mean $4.60 \mu \mathrm{g} \mathrm{m}^{-3}$ ). The regional traffic was found to be of minor importance accounting only for $0.83 \mu \mathrm{g} \mathrm{m}^{-3}$ of $\mathrm{PM}_{2.5}$ concentrations. As discussed by Tunved et al. (2003), there is a gradient in background aerosol concentrations in the Nordic region with highest concentrations in the South and decreas- ing towards the North. Thus, it is expected to have a larger absolute contribution of LRT to mass concentrations in Denmark compared to Northern Sweden. Local RWC influence on aerosol concentrations might be lower in Denmark since winters are milder than in Northern Sweden. This is associated to lower heat demand (lower emissions) and more unstable lower atmosphere (favors the vertical dispersion of pollutants). 
Figure 9 displays the diurnal contribution of the modeled factors to the $\mathrm{PM}_{10}, \mathrm{PM}_{1}, \mathrm{M}_{\mathrm{LAC}}$, and $\mathrm{N}_{25-606}$ concentrations for weekdays and weekends. Krecl et al. (2008) showed that measured mean aerosol concentrations were statistically significantly higher on WE than on WD after 12:00 LT at 95\% confidence level when analyzing the same data set employed in this study. For all aerosol variables, the contribution of local traffic (factor 1) on weekdays shows a peak concentration at 09:00-10:00 LT and a second and smaller maximum at 20:00-21:00 LT. During weekdays, local traffic emissions increase the aerosol concentrations during the morning reaching a peak value $\sim 11: 00-12: 00 \mathrm{LT}$ while in the evening its effect is smaller and more diffuse. As shown before, the mean contribution of local traffic to the aerosol concentration is similar on weekdays and weekends. Then this large difference between weekends and weekdays for all aerosol variables is attributed by PMF to local RWC as shown in Fig. 9. On weekends, the contribution of local RWC to atmospheric aerosol is largest between 18:00 and midnight even when considering the minimum contribution (only factor 2). This result is in agreement with the findings by Kim et al. (2004) when applying PMF analysis on particle volume distributions measured in Seattle (USA) during the winter season. They identified a local RWC particle emission source based on the distinct diurnal pattern of modeled volume concentrations on weekends compared to weekdays. In Seattle, daytime contributions of this factor during weekends were lower than those of weekdays and the highest concentrations were observed on weekends between 21:00 LT and midnight.

\section{Conclusions}

This work demonstrates that is possible to estimate the emission sources of atmospheric aerosols applying PMF analysis on particle size distributions in a wood smoke-impacted residential area. Hence, this methodology could be applied to other urban sites where RWC is a substantial source of aerosol particles and particle size distribution emissions of vehicle exhaust and RWC present characteristic modes and shapes that can be properly separated and identified by PMF. The high-temporal resolution of the source apportionment allows studying in detail the diurnal variation of source contributions to ambient aerosol and also provides a better estimation of the time periods when the inhabitants are more exposed to harmful aerosol concentrations. Although the PMF factors were attributed to certain emission sources, they might still be influenced by other unknown sources or among themselves. This PMF source-receptor modeling should be complemented with chemical speciation analysis to provide a more precise source apportionment in relation to local RWC due to the overlapping of sources profiles between RWC and LRT at this receptor site. In the Nordic region, where LRT can have a large influence on particle concentrations, DMPS measurements at rural background sites close to the receptor site of interest should be conducted in future field campaigns. The results obtained in Lycksele could be generalized to other cities/towns in Northern Sweden with similar topography and meteorological conditions during winter. However, to obtain a better estimation of the contribution of the different emission sources to atmospheric aerosols at another location, a source apportionment study should be carried out in the area of interest.

\section{Appendix}

The time series of the modeled aerosol variables for each factor together with the observed data are presented in Figs. A1, $\mathrm{A} 2$, and $\mathrm{A} 3$. 


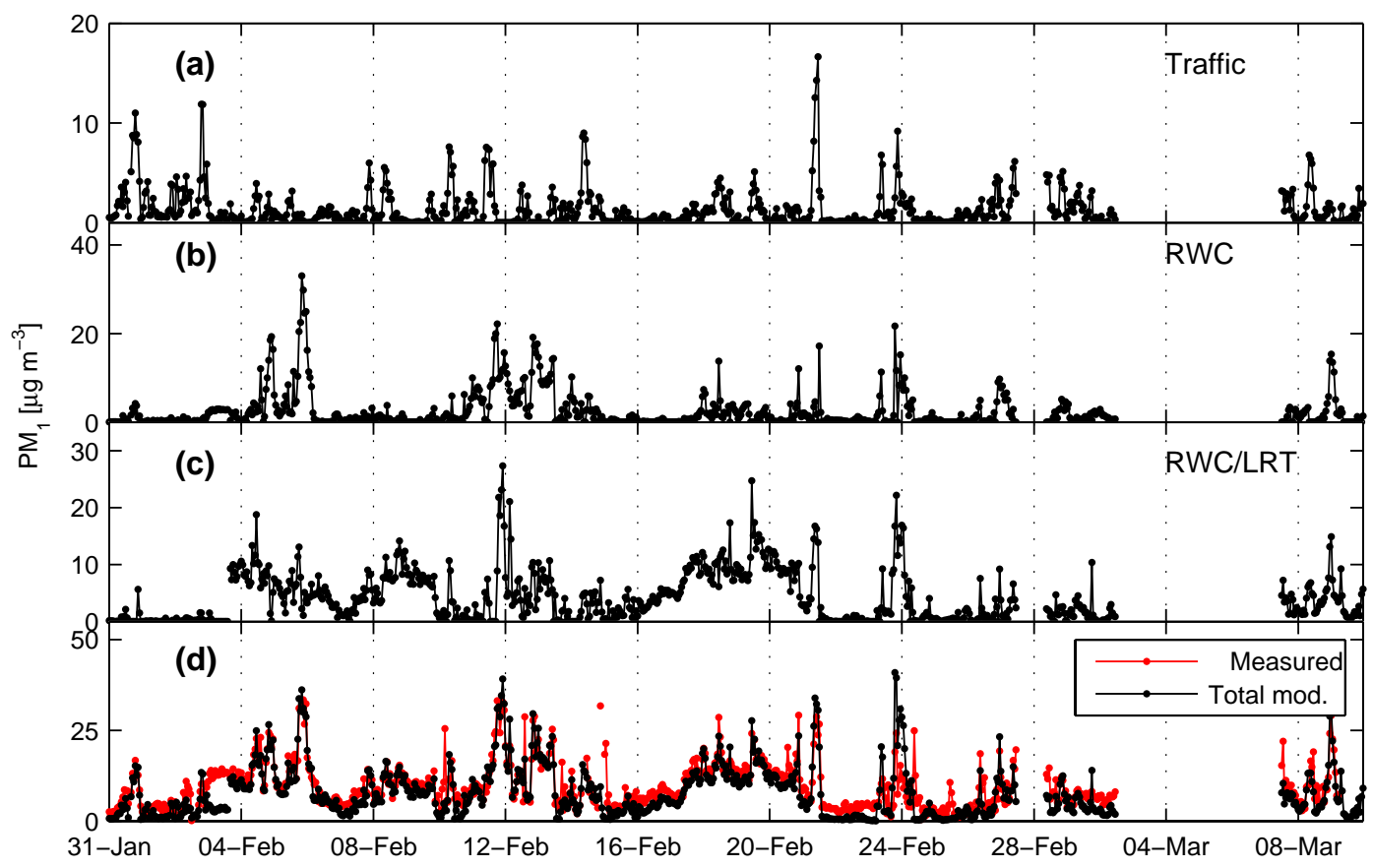

Fig. A1. Time series of modeled $\mathrm{PM}_{1}$ contribution for each factor (a), (b), (c), together with total modeled and measured $\mathrm{PM}_{1}$ concentrations (d). PMF was run with $F_{\text {peak }}=-1.4, C_{3}=0.25$, and $\alpha=4$.

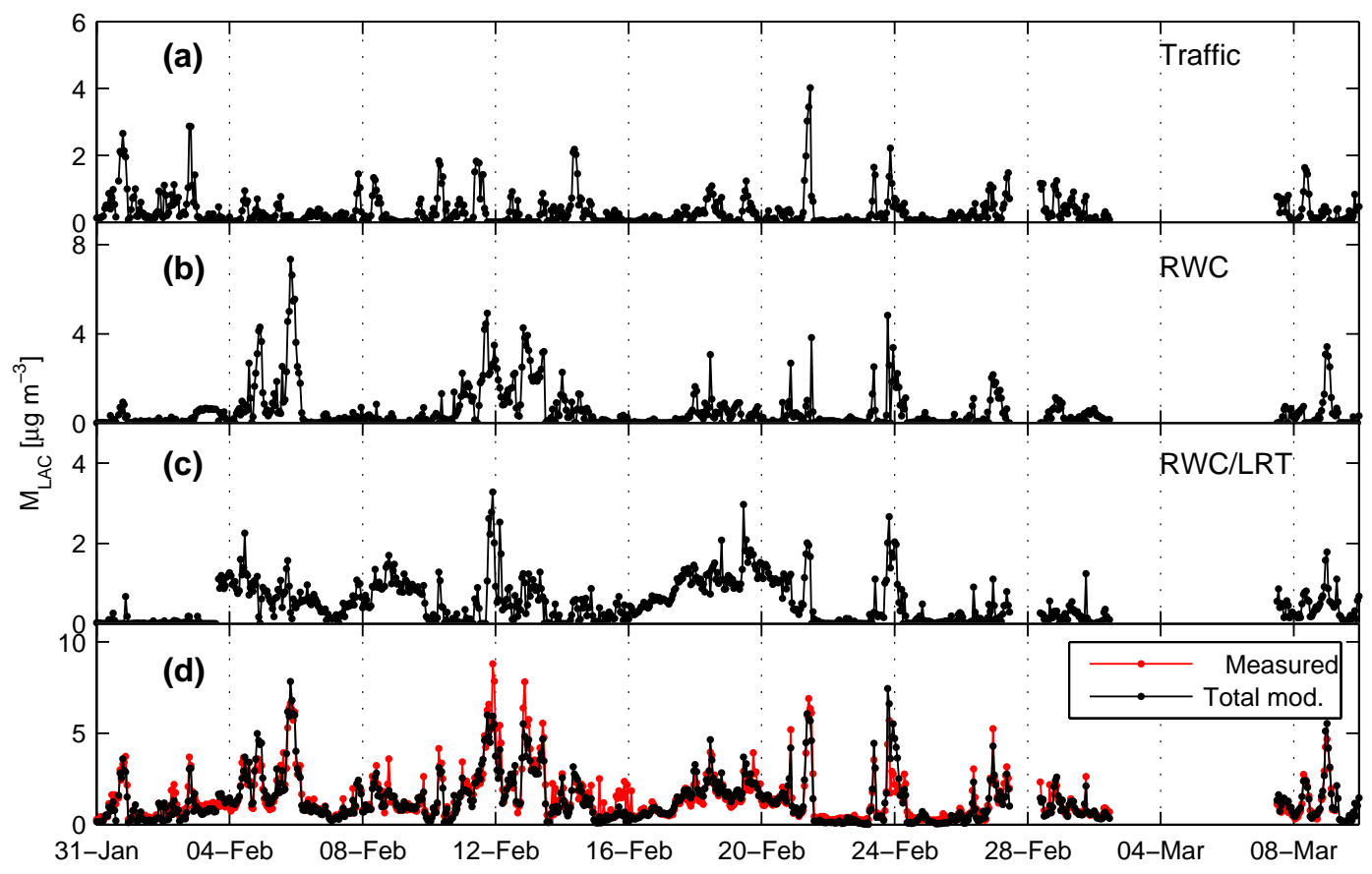

Fig. A2. Times series of modeled $\mathrm{M}_{\mathrm{LAC}}$ contribution for each factor (a), (b), (c), together with total modeled and measured $\mathrm{M}_{\mathrm{LAC}}$ concentrations (d). PMF was run with $F_{\text {peak }}=-1.4, C_{3}=0.25$, and $\alpha=4$. 


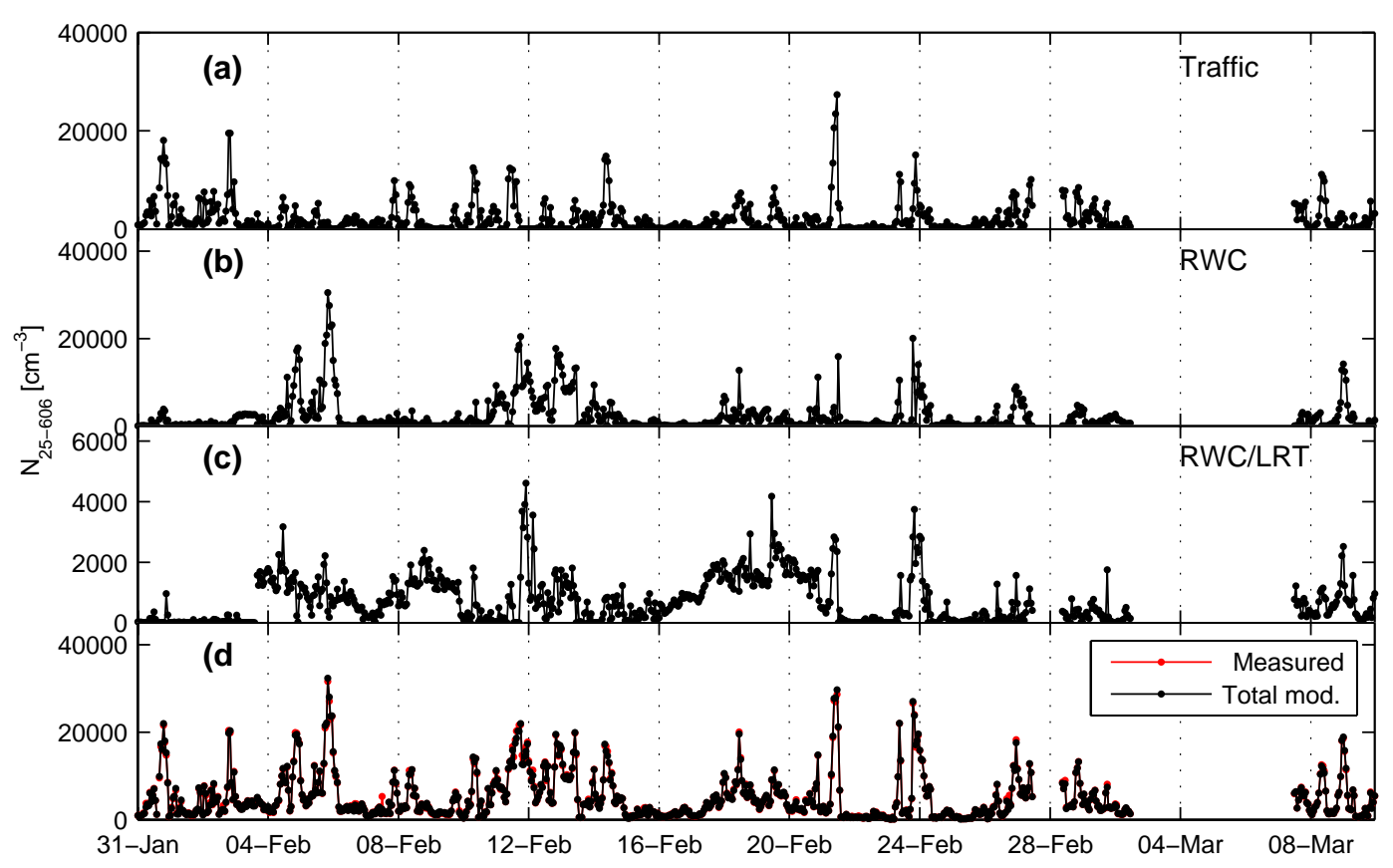

Fig. A3. Time series of modeled $\mathrm{N}_{25-606}$ contribution for each factor (a), (b), (c), together with total modeled and measured $\mathrm{N}_{25-606}$ concentrations (d). PMF was run with $F_{\text {peak }}=-1.4, C_{3}=0.25$, and $\alpha=4$.

Acknowledgements. Financial support from the Swedish Energy Agency and the Swedish Environmental Protection Agency is acknowledged. We thank T. Hennig for calculating the error in particle sizing due to flow rate fluctuations in the DMA and for useful discussions on DMPS measurement errors.

Edited by: K. Lehtinen

\section{References}

Boman, C.: Particulate and gaseous emissions from residential biomass combustion, Ph.D. Thesis, Energy Technology and Thermal Process Chemistry, Umeå University, Umeå, Sweden, available at: http://www.diva-portal.org/umu/theses/index.xsql? lang=en, 2005, last access: 25 November 2007.

Burtscher, H.: Comparison of particle emissions from different combustion systems, J. Aerosol Sci., 31, S620-S621, 2000.

Gidhagen, L., Johansson, C., Langner, J., and Olivares, G.: Simulation of NOx and ultrafine particles in a street canyon in Stockholm, Sweden, Atmos. Environ., 38, 2029-2044, 2004.

Gillies, J. A. and Gertler, A. W.: Comparison and evaluation of chemically speciated mobile source $\mathrm{PM}_{2.5}$ particulate matter profiles, J. Air Waste Ma., 1459-1480, 2000.

Glasius, M., Ketzel, M., Wåhlin, P., Jensen, B., Mønster, J., Berkowicz, R., and Palmgren, F.: Impact of wood combustion on particle levels in a residential area in Denmark, Atmos. Environ., 40, 7115-7124, 2006.

Gorin, C. A., Collet, J. L., and Herckes, P.: Wood smoke contribution to winter aerosol in Fresno, CA, J. Air Waste Ma., 56, 1584-1590, 2006.
Hedberg, E., Kristensson, A., Ohlsson, M., Johansson, C., Johansson, P. Å., Swietlicki, E., Vesely, E., Wideqvist, U., and Westerholm, R.: Chemical and physical characterization of emissions from birch wood combustion in a wood stove, Atmos. Environ., 36, 4823-4837, 2002.

Hedberg, E., Gidhagen, L., and Johansson, C.: Source contributions to $\mathrm{PM}_{10}$ and arsenic concentrations in Central Chile using positive matrix factorization, Atmos. Environ., 39, 549-561, 2005.

Hedberg, E., Johansson, C., Johansson, L., Swietlicki, E., and Brorström-Lundén, E.: Is levoglucosan a suitable quantitative tracer for wood burning?: comparison with receptor modeling on trace elements in Lycksele, Sweden, J. Air Waste Ma., 56, 1669-1678, 2006.

Hering, S. V., Kreisberg, N. M., Stolzenburg, M. R., and Lewis, G. S.: Comparison of particle size distributions at urban and agricultural sites in California's San Joaquin Valley, Aerosol Sci. Tech., 41, 86-96, 2007.

Hueglin, C., Gaegauf, C., Künzel, S., and Burtscher, H.: Characterization of wood combustion particles: morphology, mobility, and photoelectric activity, Environ. Sci. Technol., 31, 3439-3447, 1997.

Johansson, L. S., Leckner, B., Gustavsson, L., Cooper, D., Tullin, C., and Potter, A.: Emission characteristics of modern and oldtype residential boilers fired with wood logs and wood pellets, Atmos. Environ., 38, 4183-4195, 2004.

Keywood, M. D., Ayers, G. P., Gras, J. L., Gillet, R. W., and Cohen, D.: Size distribution and sources of aerosol in Launceston, Australia, during winter 1997, J. Air Waste Ma., 50, 418-427, 2000.

Khalil, M. A. K. and Rasmussen R. A.: Tracers of wood smoke, Atmos. Environ., 37, 1211-1222, 2003.

Kim, E., Hopke, P. K., Larson, T. V., and Covert, D. S.: Analysis 
of ambient particle size distributions using Unmix and positive matrix factorization, Environ. Sci. Technol., 38, 202-209, 2004.

Kocbach, A., Johansen, B. V., Schwarze, P. E., and Namork, E.: Analytical electron microscopy of combustion particles: a comparison of vehicle exhaust and residential wood smoke, Sci. Total Environ., 346, 231-243, 2005.

Krecl, P., Ström, J., and Johansson, C.: Carbon content of atmospheric aerosols in a residential area during the wood combustion season in Sweden, Atmos. Environ., 41, 6974-6985, 2007.

Krecl, P., Ström, J., and Johansson, C.: Diurnal variation of atmospheric aerosol during the wood combustion season in Northern Sweden, Atmos. Environ., 42, 4113-4125, 2008.

Kristensson, A., Johansson, C., Westerholm, R., Swietlicki, E., Gidhagen, L., Wideqvist, U., and Vesely, V.: Real-world traffic emission factors of gases and particles measured in a road tunnel in Stockholm, Sweden, Atmos. Environ., 38, 657-673, 2004.

Kristensson, A.: Aerosol particle sources affecting the Swedish air quality at urban and rural level, Ph.D. thesis, Lund Institute of Technology, Lund University, Sweden, available at: http://theses.lub.lu.se/postgrad//search.tkl?field $\backslash$ query $1=$ pubid $\backslash \&$ query $1=$ tec_936 $\backslash \&$ recordformat=display, last access: 5 November 2007, 2005.

Paatero, P. and Tapper, U.: Positive matrix factorization: a nonnegative factor model with optimal utilization of error estimates of data values, Environmetrics, 5, 111-126, 1994.

Paatero, P.: User's guide for positive matrix factorization programs PMF2 and PMF3, 2: reference, 2000.

Paatero, P., Hopke, P. K., Song, X.-H., and Ramadan, Z.: Understanding and controlling rotations in factor analytic models, Chemometr. Intell. Lab., 60, 253-264, 2002.

Paatero, P., Hopke, P. K., Begum, B. A., and Biswas, S. K.: A graphical diagnostic method for assessing the rotation in factor analytical models of atmospheric pollution, Atmos. Environ., 39, 193-201, 2005.
Reddy, C. M., Pearson, A., Xu, L., McNichol, A. P., Benner, B. A., Wise, S. A., Klouda, G. A., Currie, L. A., and Eglinton, T. I.: Radiocarbon as a tool to apportion the sources of polycyclic aromatic hydrocarbons and black carbon in environmental samples, Environ. Sci. Technol., 36, 1774-1782, 2002.

Reff, A., Eberly, S. I., and Bhave, P. V.: Receptor modeling of ambient particulate matter data using positive matrix factorization: review of existing methods, J. Air Waste Ma., 57, 146-154, 2007.

SIKA: Vehicles in counties and municipalities at the turn of the year 2005/2006, http://www.sika-institute.se/Templates/ FileInfo.aspx?filepath=/Doclib/Import/101/ss_2006_4.pdf, last access: 17 March 2008, 2006.

Statistics Sweden: Energy statistics for one- to two-dwelling buildings in 2005, Statistiska Meddelanden EN16SM0601, http:// www.scb.se/templates/Publikation _-__178027.asp, last access: 8 November 2007, 2005.

Tunved, P., Hansson, H. C., Kulmala, M., Aalto, P., Viisanen, Y., Karlsson, H., Kristensson, A., Swietlicki, E., Dal Maso, M., Ström, J., and Komppula, M.: One year boundary layer aerosol size distribution data from five Nordic background stations, Atmos. Chem. Phys., 3, 2183-2205, 2003, http://www.atmos-chem-phys.net/3/2183/2003/.

Wang, H. and Shooter, D.: Coarse-fine and day-night differences of water-soluble ions in atmospheric aerosols collected in Christchurch and Auckland, New Zealand, Atmos. Environ., 36, 3519-3529, 2002.

Wiedensohler, A., Orsini, D., Covert, D. S., Coffmann, D., Cantrell, W., Havlicek, M., Brechtel, F. J., Russell, L. M., Weber, R. J., Gras, J., Hudson, J. G., and Litchy, M.: Intercomparison study of the size-dependent counting efficiency of 26 condensation particle counters, Aerosol Sci. Tech., 27, 224-242, 1997.

Zhou, L., Kim, E., Hopke, P. K., Stainer, C. O., and Pandis, S.: Advanced factor analysis on Pittsburgh particle size-distribution data, Aerosol Sci. Tech., 38(S1), 118-132, 2004. 